\title{
Estudio comparativo entre una prueba rápida y RT-PCR tiempo real en el diagnóstico de influenza AH1N1 2009
}

\author{
Luz Araceli Castro-Cárdenas, M en E Sup,(I) Jorge M Llaca-Díaz, MSP,(I) Fernando Pérez-Chávez, D Hem,(I) \\ Irene A Gómez-Espinel, MC en Gen, ${ }^{(I)}$ Amador Flores-Aréchiga, MSP.(I)
}

\begin{abstract}
Castro-Cárdenas LA, Llaca-Díaz JM, Pérez-Chávez F, Gómez-Espinel IA, Flores-Aréchiga A. Estudio comparativo entre una prueba rápida y RT-PCR tiempo real en el diagnóstico de influenza AHINI 2009. Salud Publica Mex 20II;53:329-333.
\end{abstract}

\begin{abstract}
Resumen
Objetivo. Comparar la prueba QuickVue Influenza A+B empleando como estándar la RT-PCR tiempo real para influenza AHINI 2009. Material y métodos. Estudio retrospectivo-comparativo de 135 muestras de vías respiratorias de individuos sintomáticos para influenza procesadas de mayo 2009 a octubre 2010. Las pruebas citadas se realizaron simultáneamente. Se utilizó el software Confidence Interval Analysis 2000. Resultados. Sensibilidad 62.96; especificidad 94.44; valor predictivo negativo 62.9; valor predictivo positivo 94.44; razón de probabilidad positiva II.33 y razón de probabilidad negativa 0.39 . Se calcularon intervalos de confianza a 95. Discusión. Los valores obtenidos concuerdan con otros estudios donde la sensibilidad fluctúa de 50 a 70 y especificidad entre 90 y 95 por ciento. La prueba QuickVue Influenza $A+B$ es rápida, simple y de menor costo que el RT-PCR tiempo real, útil para identificar el tipo de virus en brotes de influenza de una población determinada.
\end{abstract}

Palabras clave: virus de la influenza A subtipo HINI; RT-PCR; valor predictivo; sensibilidad; especificidad
Castro-Cárdenas LA, Llaca-Díaz JM, Pérez-Chávez F, Gómez-Espinel IA, Flores-Aréchiga A.

Comparative study of a rapid testing with real time RT-PCR for diagnosis of influenza AHINI 2009. Salud Publica Mex 20I 1;53:329-333.

\begin{abstract}
Objective. Compare QuickVue Influenza $A+B$ test with real-time RT-PCR for the diagnosis of influenza AHINI 2009. Material and Methods. Retrospective-comparative study of I35 respiratory specimens from individuals with symptoms of influenza processed from May 2009 to October 20 I0.The above mentioned tests were performed simultaneously. For statistic analysis the software of Confidence Interval Analysis 2000 was used. Results. The parameters obtained were: sensitivity 62.96; specificity 94.44 ; negative predictive value 62.9; positive predictive value 94.44 ; positive likelihood ratio II.33; negative likelihood ratio 0.39 . Confidence intervals to 95, were calculated to all of the above data. Discussion. The test QuickVue Influenza A+B is a rapid, simple test, with lower cost than real-time RT-PCR useful for identifying the type of virus outbreaks of influenza in a given population. It correlates well with more specific test and similar reports.
\end{abstract}

Key words: influenza A virus subtype HINI; RT-PCR; predictive value; sensitivity; specificity

(I) Departamento de Patología Clínica de la Facultad de Medicina. Universidad Autónoma de Nuevo León. Nuevo León, México.

Recibido: julio 20II - Aceptado: agosto 20II

Autor de correspondencia: Dr.Amador Flores Aréchiga. Departamento de Patología Clínica, Facultad de Medicina, Universidad Autónoma de Nuevo León. Av. Francisco I. Madero y José E. González s/n Col. Mitras Centro. 64460 Monterrey, Nuevo León, México

Correo electrónico: amador_flores@hotmail.com 
$A^{p}$ partir de abril de 2009 se inició una pandemia causada por una nueva mutación del virus de influenza A subtipo H1N1 que en un principio se denominó "porcina", después "mexicana" y finalmente "2009". ${ }^{1}$

Existen varios métodos diagnósticos para identificar el virus de la influenza. ${ }^{2-4}$ La prueba rápida empleada consiste en un inmunoanálisis de flujo lateral que utiliza anticuerpos monoclonales de alta sensibilidad específicos para la detección de los antígenos de la influenza A y B. Esta prueba se presenta en forma de tirillas. En el centro de la tirilla se encuentra una zona "control", por arriba de ella están colocados los anticuerpos de tipo A y por debajo los del B. La zona de control siempre se tiñe de azul y es la única línea presente en una muestra negativa. Si la muestra contiene antígenos A o B detectables, aparecerá, además, una línea rosa (figura 1).

Es importante aclarar que esta prueba no tiene la capacidad de identificar en forma específica el virus AH1N1 2009, sólo lo reconoce como tipo A. ${ }^{5}$

El método molecular que se empleó corresponde a la reacción en cadena de la polimerasa de transcrip-

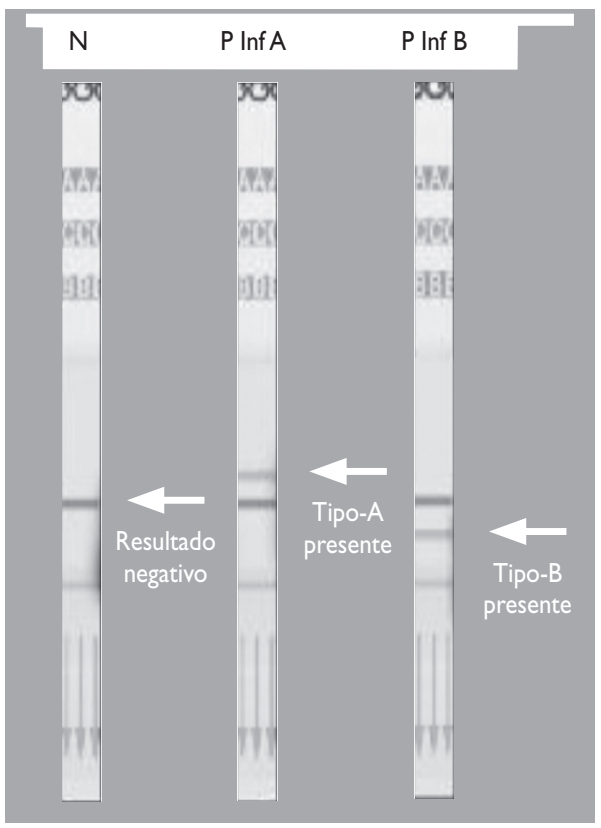

$\mathrm{N}$ : Negativo

$P \operatorname{lnf} A$ : Positivo para A

$P$ Inf $B$ : Positivo para influenza $B$

Fuente: Referencia 5

Figura I. Resultados de la prueba Quickvue Influenza A+B tasa inversa en tiempo real (RT-PCR tiempo real) para influenza AH1N1 2009, el cual es considerado, junto con el cultivo, como prueba estándar. El primer paso consiste en extraer y cuantificar el ARN viral, luego se realiza la reacción de transcripción en reversa con la que se obtiene ADN complementario; enseguida, con el empleo de iniciadores específicos y de ciclos repetitivos, se realiza la PCR tiempo real de cuatro genes distintos: RNasaP control para validar todo el proceso; InfA detecta la forma universal del virus de la influenza A; swInfA identifica todos los virus de influenza A porcina; swH1 detecta el gen de la hemaglutinina H1 de la influenza 2009. La muestra debe ser positiva para la curva de RNAsaP antes del ciclo 37, lo que indica que la cantidad y calidad del ARN es aceptable para el estudio. Un estudio es considerado positivo para influenza AH1N1 2009 si ambas curvas de crecimiento de la reacción de INFA y la del respectivo subtipo (swInfA o SwH1) cruzan la línea de umbral en los primeros 40 ciclos (figura 2A). Una muestra es considerada negativa si ninguna de las curvas de crecimiento de INFA cruza el umbral en los primeros 40 ciclos (figura $2 \mathrm{~B}$ ). ${ }^{6}$

El objetivo de este estudio consistió en evaluar la prueba rápida QuickVue Influenza $A+B$ empleando como estándar la RT-PCR tiempo real para influenza AH1N1 2009.

\section{Material y métodos}

Población en estudio. Se colectaron muestras de exudado faríngeo o nasal de pacientes con síntomas de influenza, en el período de mayo de 2009 a octubre de 2010. Fueron transportadas desde los diferentes servicios del hospital en medio viral BD recomendado por la Secretaria de Salud. Cuando fue necesario conservarlas, se almacenaron a $-70^{\circ} \mathrm{C}$.

En total se realizaron 1695 pruebas rápidas y 337 de RT-PCR tiempo real. De ellas, la prueba rápida fue positiva en 530 y negativa en 1165 . Al RT-PCR tiempo real le correspondieron 131 positivos y 206 negativos. En muchos casos, sólo se hicieron pruebas rápidas y en otros sólo RT-PCR tiempo real. Como el propósito de este estudio es evaluar la prueba rápida empleando como estándar la RT-PCR tiempo real para influenza AH1N1 2009, fue necesario identificar las muestras que se realizaron en forma simultánea. Llenaron este último criterio un total de 135 , que son el universo de este estudio.

Para la prueba rápida se utilizó el Kit QuickVue Influenza A+B Ref 97021 bajo los lineamientos especificados por el fabricante. ${ }^{5}$ En el caso de la prueba RTPCR tiempo real se realizó la extracción de ARN con 


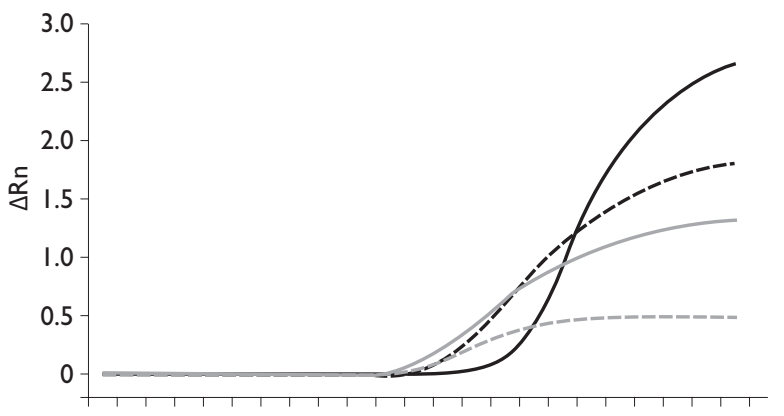

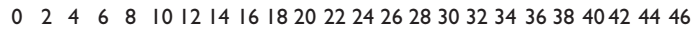

Ciclo

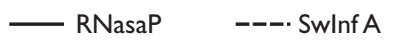

Panel A: muestra positiva

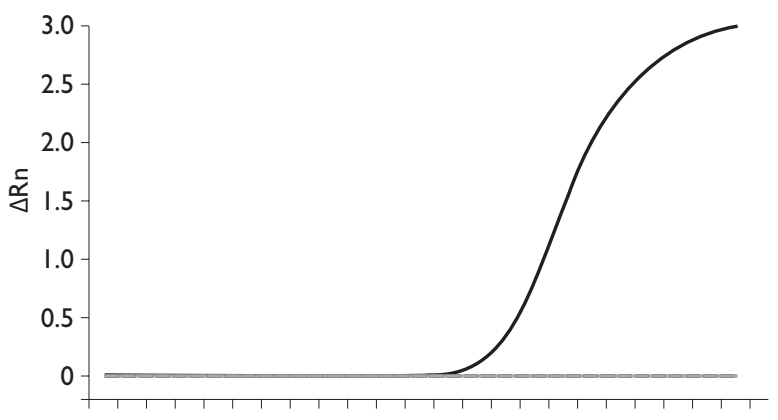

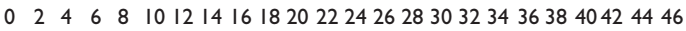

Ciclo

$\longrightarrow$ Sw HI ---. InfA

RNasaP: control; InfA: detecta la forma universal del virus de la influenza A; swlnfA: identifica todos los virus de influenza A porcina; swHI: detecta el gen de la hemaglutinina $\mathrm{HI}$ de la influenza 2009

\section{Figura 2. Resultados del RT-PCR tiempo real para influenza AHINI 2009}

el paquete QIAmp viral RNA Minikit (250), catálogo 52906, y para la amplificación el paquete de sondas INFSWPANEL, la Taq SSIII - STEP QRT-PCR 500, catálogo 11732088, y el termociclador StepOne Real Time PCR System, bajo los lineamientos establecidos en el protocolo del Centro de Control de Enfermedades (CDC por sus siglas en inglés). ${ }^{6}$

Criterio de inclusión. Todas las muestras en las que se practicó de manera simultánea la prueba rápida y el RT-PCR tiempo real.

Análisis estadístico. Para la obtención de los parámetros se empleó el programa CIA, por sus siglas en inglés (Confidence Interval Analysis 2000). ${ }^{7}$ Se eligieron los siguientes parámetros: sensibilidad, especificidad, valor predictivo positivo (VPP), valor predictivo negativo (VPN), razón de probabilidad (likelihood ratios) positiva y negativa. A todos los anteriores se les calcularon los intervalos de confianza (IC) a 95.8

El estudio fue aprobado por el Comité de Ética de la Facultad de Medicina y Hospital Universitario Dr. José Eleuterio González, de la Universidad Autónoma de Nuevo León (UANL).

\section{Resultados}

De las 135 muestras analizadas, 70 fueron de hombres y 65 de mujeres, cuyas edades fluctúan entre los 7 meses y 68 años.

El cuadro I distribuye los resultados de la prueba rápida comparados con el RT-PCR tiempo real, distin-

\section{Cuadro I \\ Prueba Rápida comparada con RT-PCR tiempo Real}

$$
\begin{array}{cc}
\text { RT-PCR tiempo real } \\
\text { positiva }
\end{array} \begin{gathered}
\text { RT-PCR tiempo real } \\
\text { negativa }
\end{gathered} \text { Total }
$$

\begin{tabular}{lcccc} 
Prueba rápida positiva & (a) $\begin{array}{c}5 \mathrm{I} \\
\text { (VP) }\end{array}$ & \begin{tabular}{c} 
(b) $\begin{array}{c}3 \\
\text { (FP) }\end{array}$ \\
\hline Prueba rápida negativa
\end{tabular} (c) $\begin{array}{c}30 \\
\text { (FN) }\end{array}$ & $\begin{array}{c}\text { (d) } \\
51 \\
\text { (VN) }\end{array}$ & 81 \\
\hline Total & $\begin{array}{c}8 \mathrm{I} \\
(\mathrm{VP}+\mathrm{FN})\end{array}$ & $\begin{array}{c}54 \\
(\mathrm{FP}+\mathrm{VN})\end{array}$ & 135
\end{tabular}

VP: verdadero positivo FP: falso positivo

FN: falso negativo $\quad \mathrm{VN}$ : verdadero negativo 
guiéndose 30 falsos negativos que representan 37\% y 3 falsos positivos que son $5.5 \%$.

Al utilizar el programa CIA para el análisis estadístico se encontraron los siguientes valores: sensibilidad 62.96 con IC de 52.1 a 72.7; especificidad 94.44, IC 84.9 a 98.1; VPP 94.44, IC 84.9 a 98.1; VPN 62.96, IC 52.1 a 72.7; concordancia global de 75.55, IC 67.7 a 82.0; razón de probabilidad positiva 11.33, IC 3.73 a 34.47; razón de probabilidad negativa 0.39 , IC 0.29 a 0.53 .

\section{Discusión}

Los parámetros que se determinaron para conocer la validez de la prueba diagnóstica fueron sensibilidad y especificidad. Los valores obtenidos en este trabajo (sensibilidad 62.96 y especificidad de 94.44 ) concuerdan con los obtenidos en otros estudios donde los rangos de sensibilidad van de 50 a $70 \%$ y especificidad entre 90 y 95 por ciento. ${ }^{4,5,8-11}$ El valor de sensibilidad indica que casi cuatro de cada diez enfermos de influenza no son detectados por esta prueba.

Los parámetros que se determinaron para conocer la seguridad de la prueba fueron VPP, VPN, razón de probabilidad y concordancia global.

El VPP y el VPN se modifican de acuerdo con la prevalencia de la enfermedad en un lugar determinado. Cuando la prevalencia de la influenza es alta el VPP es alto y el VPN es bajo, lo que coincide con los resultados obtenidos en este trabajo. ${ }^{12,13}$

El VPP encontrado (94.44) indica que una prueba rápida positiva posee una alta probabilidad de relacionarse con influenza AH1N1. Para el VPN (62.93) el comentario anterior sobre sensibilidad es válido en la misma proporción.

Un parámetro de utilidad en investigaciones clínicas lo representa la razón de probabilidad positiva que también se conoce como razón de verosimilitud. Piédrola señala que una razón de probabilidad o verosimilitud positiva mayor de 10 es excelente, de 5 a 10 buena, de 2 a 5 regular y de 1 a 2 deficiente. ${ }^{12}$ En este estudio, el valor encontrado para este parámetro es de 11.33, lo que coloca a la prueba rápida como excelente. En el caso de la razón de probabilidad negativa su valoración es inversa al de la prueba positiva, lo que significa que entre más se acerque a cero el resultado, mejor es la prueba negativa. El valor encontrado para la prueba negativa es de 0.39 , por lo que se puede afirmar que la prueba rápida es de utilidad tanto por su valor de la razón de probabilidad positiva como por el de la negativa.

La prueba rápida se realiza en un tiempo máximo de 15 minutos, no requiere equipo sofisticado ni entrenamiento especializado del analista y el costo aproximado por muestra en este estudio fue de $\$ 220.00$; en cambio, el costo por muestra del RT-PCR tiempo real fue de $\$ 650.00$. Esta última técnica requiere de equipo costoso, analistas especializados y un tiempo aproximado de cinco horas para su realización

En 2011 se han presentado brotes de influenza A H1N1 2009 en Chihuahua. Si bien hasta el momento no tienen la incidencia y prevalencia de los años 20092010, es recomendable estar alerta ante la posibilidad de una reactivación. En tal caso pueden tener importancia estudios como el presentado. ${ }^{14}$

\section{Conclusión}

Los valores de sensibilidad, especificidad y valor predictivo positivo y negativo señalan que la prueba rápida es aceptable en las condiciones en que se justifique su utilización, ya sea por su sencillez, rapidez, menor costo y por no requerir recursos humanos altamente especializados. Lo anterior se respalda también con los valores de la razón de probabilidad encontrados. Comprobamos que la prueba rápida es de utilidad como una prueba de monitoreo para identificar brotes de influenza, ya que resultados positivos encontrados en individuos que conviven en un sitio determinado y con cuadro clínico sospechoso se relaciona con una alta probabilidad de infección por influenza AH1N1 2009. Es de esperarse que los fabricantes de las pruebas rápidas mejoren el límite de detección de los antígenos virales, lo que le daría una mayor sensibilidad, aunque ésta no podría igualar la sensibilidad de la RT-PCR tiempo real por las características propias de la técnica.

Declaración de conflicto de intereses: Los autores declararon no tener conflicto de intereses.

\section{Referencias}

I. Ison M, Lee N. Influenza 2010-20I I: Lessons from the 2009 pandemic. Cleveland Clinic Journal of Medicine 20I0; 77: (II) 8I2-820.

2. Ramos-Jiménez J. Infectología clínica. México: El Manual Moderno, 2008: 313-323.

3. Takahashi $\mathrm{H}$, Otsuka Y, Patterson B. Diagnostic test for influenza and other respiratory viruses: determining performance specifications based on clinical setting.J Infect Chemother 2010; 16: 155-161.

4. Gavin PJ,Thomson RB. Review of rapid diagnostic test for Influenza. Clinical and Applied Inmunology Reviews 4: 2003; 15I- 172. 5. Quidel Corporation. [sitio de internet]. San Diego: QuickVue Influenza A+B test. [Consultado 2009 marzo 29]. Disponible en: http://www.quidel.com/products/product_detail. php? prod $=101$ \&group $=\mid$ \&show $=$ spec

6. Centro para el Control y la Prevención de Enfermedades. [sitio de internet]. Atlanta: $C D C$ protocol of realtime RTPCR for swine influenza $A$ (HINI). Última actualización 30 de abril de 2009. [Consultado 2009 abril I]. Disponible en: http://www.who.int/csr/resources/publications/ swineflu/CDCrealtimeRTPCRprotocol_20090428.pdf) 
7. Altman D, Machin D, Bryant T, Gardner M. Statistics with confidence. 2a. edición. Bristol: BMJ, 2000.

8. Altman D, Bland J. Diagnostic test: sensitivity and specificity. BM] I994; 308:1552.

9. González J, Iglesias JM, Romero Y, Chávez C, Gay JG, Rivas R. Costoefectividad en la detección de influenza $\mathrm{HINI}$ : datos clínicos versus pruebas rápidas. Rev Panam Salud Publica 201 I;29 (I): I-7.

I0. Figueroa C, Núñez L,Aranda D, Gómez S, Osorio E,Vargas H. Análisis de concordancia de cuatro pruebas rápidas para la detección de influenza A en Bogotá. Univ Med Bogotá (Colombia) 2009;50 (4): 444-45।

I I. Ginocchio CC, Zhang F, Manji R,Arora S, Bornfreund M, Falk L, et al. Evaluation of multiple test methods for the detection of the novel 2009 influenza A (HINI) during the New York City outbreak. Journal Clinical Virology 2009;45: 191-195.
12. Delgado M, Llorca J. Estudio de las pruebas diagnósticas. En: PiédrolaGil. Medicina preventiva y salud pública $10^{\mathrm{a}}$ ed. Barcelona: MASSON, 200I:I45-I55.

13. Atmar R, Baxter B, Domínguez E, Taber L. Comparison of reverse transcription-PCR with Tissue culture and other rapid diagnostic assays for detection of type A Influenza virus. J Clin Microbiol 1996; 2604-2606. 14. Centro Nacional de Vigilancia Epidemiológica y Control de Enfermedades [sitio de internet]. México: Influenza "En Chihuahua". Última actualización 30 de marzo de 20I I. [Consultado 20I I abril 2]. Disponible en: http://www.cenavece.salud.gob.mx/interior/ influenza20I I.html 